\section{Call for extended moratorium}

PREsIDENT Clinton on 3 July called on the other nuclear powers to join the United States in a moratorium on nuclear testing that he has ordered to be extended for at least 15 months. Saying that "if these nations will now join us in observing this moratorium, we will be in the strongest possible position to negotiate a comprehensive test ban", he also warned that the United States would move quickly to conduct nuclear tests if there was any resumption of testing by another country before October 1994. British testing in recent years has been conducted only at the main United States test site in Nevada, and President Yeltsin has expressed Russian support for a comprehensive ban, so the main question now is what France and China will do. France has been under a recent moratorium, but has a new government. China carried out two nuclear tests in 1992 (one of them, at about 600 kilotonnes, the largest underground nuclear explosion by far since the mid-1970s). A comprehensive test ban may be closer than at any time since the efforts of Kennedy, Khruschev and Macmillan in the early 1960 s - but this Pandora's box will not close easily.

P.G.R.

will stem directly from deployment of new seismic instrumentation.

In recent years, seismic stations of a new type have been installed around the world for purposes of geophysical research (G. van der Vink, IRIS consortium). Their distinguishing characteristics include broadband digital recording, and the ability to send data from remote sites, by modem and/or Internet connection, on request from any interested user. The global network has been a major effort of the international seismological research community, and its performance will, it is hoped, continue to improve. By combining the data from current and planned stations, it is estimated that all seismic events in Eurasia above about magnitude 3.8 could be detected with high confidence (J. Claassen, Sandia National Laboratory). The network performs even better than this in Central Asia, in large part because IRIS (a group of about 80 research institutions) has recently installed state-of-the-art seismometers and recording systems on territory of the former Soviet Union.

But the research community's network alone should not bear the burden of monitoring compliance with a weighty new treaty. If an event such as a nuclear test by a new state is very unlikely - but would lead to sweeping policy changes if it occurred - then the United States government, for one, would need a very reliable monitoring system (L. Turnbull, Central Intelligence Agency). The Advanced Research Projects Agency (ARPA) of the United States Defense Department in 1992 proposed the need to monitor all countries of high interest for signals of magnitude 2.5 and above (representing 1 kilotonne fully decoupled); to monitor globally to about magnitude 3-3.5 (about 10 kilotonnes fully decoupled); and to be able to locate seismic sources to within 10 kilometres "in order to bring other assets to bear" (Turnbull). These are demanding requirements, and some might say unattainable, as more than 50,000 earthquakes and several thousand chemical explosions each year give signals above magnitude 3 . In practice, monitoring below magnitude 3.5 is needed only in regions within which decoupling is plausible. Which are these regions? This question will influence the new effort needed in building a monitoring network. ARPA has been a strong proponent of building arrays of seismometers (typically 10 or more instruments deployed in an area a few kilometres across) to achieve better signal-to-noise ratios than single stations. A subcommittee of the United Nations in Geneva, known as the Group of Scientific Experts (GSE), has conducted technical tests funded extensively by ARPA to exchange seismic data between arrays and single stations in different countries. The GSE has plans ( $R$. Alewine, ARPA) for a new international seismic centre that would continuously receive data from a global network of about 50 stations and arrays, backed up by a secondary network of stations from which data could be requested as needed, for detection and location of earthquakes and explosions.

The Clinton administration has yet to decide whether the GSE approach should receive support. It would be rational first for a decision to be made on the monitoring capability required for various countries, as a basis for negotiating new limitations on nuclear testing. If an effective end to nuclear testing is desired, but a comprehensive ban is deemed unachievable because small explosions might go undetected, then one approach would be a treaty banning all explosions at and above a certain size, together with an indefinite moratorium on all nuclear explosions below that size. Such an approach was developed in 1960-62 by the United States and the Soviet Union; with a treaty threshold set initially at, say, magnitude 4 , perhaps it can succeed in the 1990s.

Paul G. Richards is at the Lamont-Doherty Earth Observatory, Columbia University, Palisades, New York 10964, USA.

\section{Chiral practice}

CARBON chemistry developed a new twist when the fullerene $C_{76}$ turned out to exist in two enantiomeric forms (R. Ettl et al. Nature 353, 149-153; 1991). But how might one separate the two? Lacking a nanoscale equivalent of Pasteur's tweezers, J. M. Hawkins and A. Meyer (Science 260, 1918-1920; 1993) have taken the chemical approach of tagging the two twisted carbon cages with a chiral ligand. Each enantiomer of the ligand has a preference for just one of the two $\mathrm{C}_{76}$ stereoisomers. So separating the tagged and untagged products, and then removing the ligand from the tagged variant, yields 97 percent pure, optically active $\mathrm{C}_{76}$ fullerenes.

\section{Blood and guts}

To reproduce its kind the female mosquito needs to drinkblood: two blood meals suffice to fuel oogenesis. But the blood proteins must first be broken down by gut enzymes, among which, as H.-M. Müller et al. (EMBO J. 12, 2891-2900; 1993)

have now shown, a pair of serine proteases, with the sequence attributes of trypsins, are prominent. Other trypsinlike sequences could be identified in the genome, but the two that Müller et al. have expressed in Escherichia colido indeed digest blood proteins in vitro. Moreover their messenger RNAs appear in the mosquito gut only after the second blood meal. The interesting questions now are how feeding provokes transcription of the trypsin genes, and whether an antitrypsin for example, administered to the host, could spell death to the mosquito with more certitude than a folded newspaper.

\section{Looking back}

SOME people just have to be different. Flouting the custom of using a microscope to investigate a sample, L. Montelius and J. O. Tegenfeldt have employed a cleverly designed sample surface to gaze at the tip of their atomic force microscope (Appl. Phys. Lett. 62 , 2628-2630; 1993). In scanning force microscopy, the shape of the tip is convoluted with that of the sample surface in the image, and the effects can be hard to remove. Montelius and Tegenfeldt get around this by etching an indium phosphide surface into tiny columns which look, in the scanning electron microscope, like an army of miniature villi. Being so much thinner than the tip, the columns act in effect as an array of delta functions. The image produced is a corresponding array of pyramidal tip shapes, one for each column, and broadened only slightly by their 40-50 nm diameter. Molecules attached to the microscope tip itself could, say the authors, be imaged simultaneously by dozens of the columns, giving a painless increase in the statistical significance of each scan. 